\title{
Síndrome de Asherman: Diagnóstico y manejo simplificado
}

\author{
Eyder Burbano Adrada, M.D.*
}

\section{RESUMEN}

OBJETIVO: Determinar la utilidad de la sonohisterografía y la dilatación uterina en el diagnóstico y manejo del síndrome de Asherman.

METODO Y PACIENTES: Se incluyeron 10 pacientes: Seis tenían antecedente de legrado postaborto, dos con legrado postparto, una con endometritis y legrado postparto y una con cirugía de Strassman.

RESULTADOS: En las 10 pacientes la sonohisterografía mostró la sinequia y su ubicación; en 7 pacientes el desprendimiento de las adherencias intrauterinas con dilatadores de Hegar fue exitosa, en una pacientes con adherencias gruesas y ubicadas en la parte superior de la cavidad endometriaI, la dilatación no fue posible y 2 pacientes prefirieron no someterse a tratamiento.

CONCLUSIONES: La sonohisterografía es un recurso diagnóstico efectivo en pacientes con síndrome de Asherman y el desprendimiento de las adherencias intrauterinas con dilatadores de Hegar para su manejo.

PALABRAS CLAVES: Síndrome de Asherman, sinequia, adherencia intrauterina, sonohisterografía.

\section{SUMMARY}

OBJECTIVE: To determine the utility of the sonohisterografía and the uterine dilation in the diagnosis and handling of the syndrome of Asherman.

METHOD AND PATIENT: 10 patients were included: Six had antecedent of postabortum curettage, two with postchildbirth curettage, a with endometritis and curettage alter delivery and one with surgery of Strasman.

RESULTS: In the 10 patients the sonohisterografía showed sinequia and its location; in 7 patients the loosening of the intrauterine adhesions with dilators of Hegar was successful, in one patients with heavy adhesions and located in the superior part of the endometriaI cavity, the expansion was not possible and 2 patients preferred not to be put under processing.

CONCLUSIONS: The sonohisterografía is a resource effective diagnosis in patients with syndrome of Asherman and the loosening of the intrauterine adhesions with dilators of Hegar for his handling.

KEY WORDS: Asherman of syndrome, sonohisterografía, sinequia, intrauterine adherence.

\section{Introducción}

La amenorrea traumática, observada y descrita por Asherman en 1948, como un proceso que se desarrolla a consecuencia de un legrado después de un embarazo, y que describía como la obliteración parcial o completa de la cavidad uterina debido a sinequias o adherencias traumáticas. Posteriormente en 1970 Carmichael también destacaba el papel etiológico de la endometritis y el legrado uterino en las 4 semanas siguientes al aborto o al parto a término (1).

Esta complicación que no es otra cosa que una "ablación traumática" del endometrio, constituye en esencia el Principio en el cual se basa la hoy conocida ablación

Gineco-Obstetra del Centro de Diagnóstico Perinatal. Clínica del I.S.S. Clínica Comsalud. Popayán-Colombia. endometrial que se realiza por histeroscopia y se presenta como una alternativa a la histerectomía, en pacientes con menorragia.

El diagnóstico de este síndrome resulta fácil, si se tiene en mente; es preciso sospecharlo en pacientes con hipo o amenorrea y antecedente de legrado postaborto o postparto. También se describe después de partos, cesáreas, retención y extracción de placenta, endometritis, miomectomías, abortifacientes químicos y radiación intracavitaria (2).

Confirmar el diagnóstico y documentarlo, puede resultar difícil, esto, debido a que actualmente el método diagnóstico de elección, es la histeroscopia (3), recurso al cual no tienen acceso todas las pacientes, ya por disponibilidad o por costos.

La histerosalpingografía no es un recurso ideal en esta patología, ya que, la mayoría de las veces solo muestra un 
defecto en el llenado en la cavidad, endometrial. La ecografía transvaginal puede mostrar interrupciones de la línea endometrial que hacen sospechar este síndrome.

La sonohisterografía, que ha mostrado gran utilidad en pacientes con hemorragia uterina anormal, resultó de gran utilidad en le diagnóstico de este síndrome ya que permite delimitar las adherencias lográndose obsevar su espesor y ubicación dentro de la cavidad endomerial.

\section{Pacientes y método}

En un período de 6 años, a partir de Noviembre de 1993 a Noviembre de 1999 , se revisaron las historias de 10 pacientes, siete que habían consultado por hipomenorrea $\mathrm{y}$ tres por amenorrea. Seis tenían antecedente de legrado postaborto, dos legrado postparto, una con endometritis y legrado postparto y una con cirugía de Strassman. A 4 pacientes se les había realizado un segundo legrado por

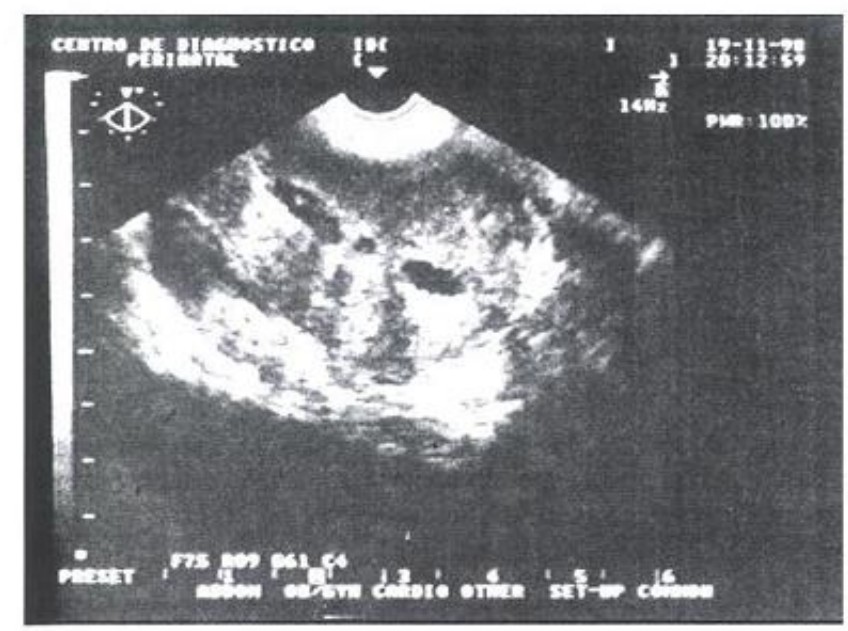

Figura 1.0008i01

EL LÍQUIDO INYECTADO EN LA CAVIDAD

ENDOMETRIAL DIFUNDE POR AQUELLOS SITIOS

QUE NO ESTÁN ADHERIDOS, PONIENDO EN EVIDENCIA LAS SINEQUIAS. persistencia de sangrado después de un primer legrado postaborto y al igual que en la serie de Westendorp (4), es este, el antecedente que más se repite.

Cinco pacientes tenían histerosalpingografía previa, 4 reportaban defecto de llenado de la cavidad endometrial y una a quien no fue posible realizarle el procedimiento.

A las 10 pacientes se les realizó sonohisterografía utilizando catéter de inseminación intrauterina de $2.3 \mathrm{~mm}$ KDF-2.3 (Unimar) para instilar la solución salina el la cavidad endometrial (5).

\section{Resultados}

A las 10 pacientes se les realizó sonohisterografía, en todas se lograron imágenes que confirmaron el diagnóstico.

Antes de realizar la sonohisterografía 2 pacientes con prolactina $>20 \mathrm{ng} / \mathrm{ml}$ recibieron tratamiento con bromocriptina, sin lograr normalizar su menstruación.

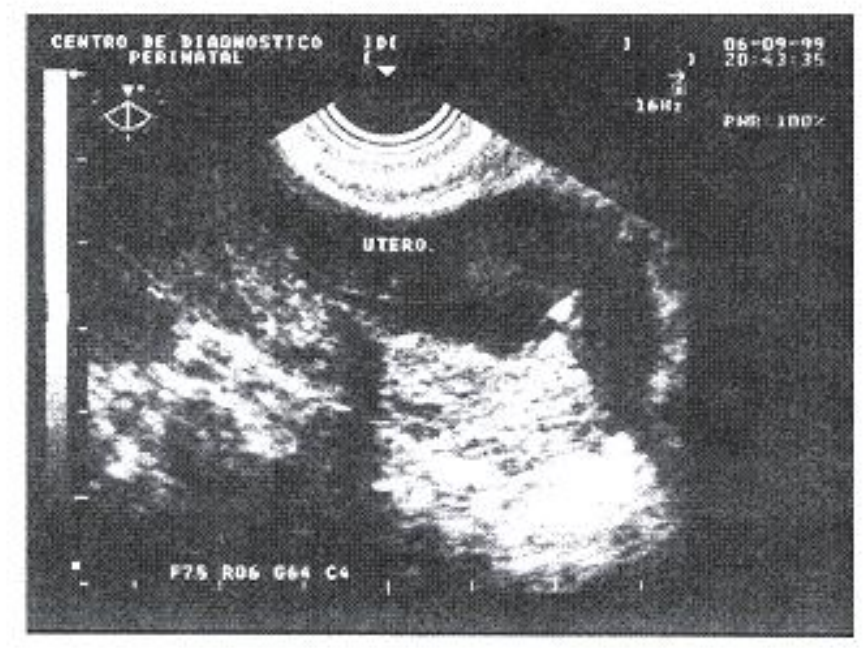

Figura 2. 0008i02

EN AUSENCIA DE ADHERENCIAS INTRAUTERINAS, EL LIQQUIDO EXPANDE LA CAVIDAD ENDOMETRIAL.

Tabla 1

\begin{tabular}{|clllc|}
\hline Pte No. & Edad & Paridad & Antecedentes & $\begin{array}{c}\text { Interés } \\
\text { Obst. }\end{array}$ \\
\hline 1 & 19 & G2 P1 A1 & Un legrado pa & No \\
2 & 35 & G4 P3 A1 & Un legrado pa & $<20 \mathrm{ng} / \mathrm{ml} / \mathrm{ml}$ \\
3 & 41 & G1 A1 & Strassman & $<20 \mathrm{ng} / \mathrm{ml}$ \\
4 & 34 & G4 C1 A3 & Dos legrados pa & $<20 \mathrm{ng} / \mathrm{ml}$ \\
5 & 25 & G1 P1 & Endometritis pp & $<20 \mathrm{ng} / \mathrm{ml}$ \\
6 & 22 & G2 P2 & Un legrado pp & $<20 \mathrm{ng} / \mathrm{ml}$ \\
7 & 39 & G3 A3 & Dos legrados pa & $<20 \mathrm{ng} / \mathrm{ml}$ \\
8 & 32 & G2 P1 A1 & Un legrado pp & $<20 \mathrm{ng} / \mathrm{ml}$ \\
9 & 36 & G4 P2 A2 & Dos legrados pa & $<20 \mathrm{ng} / \mathrm{ml}$ \\
10 & 29 & G3 C1 A2 & Dos legrados pa & $35 \mathrm{ng} / \mathrm{ml}$ \\
\hline
\end{tabular}

pa: postaborto; pp: postparto. 


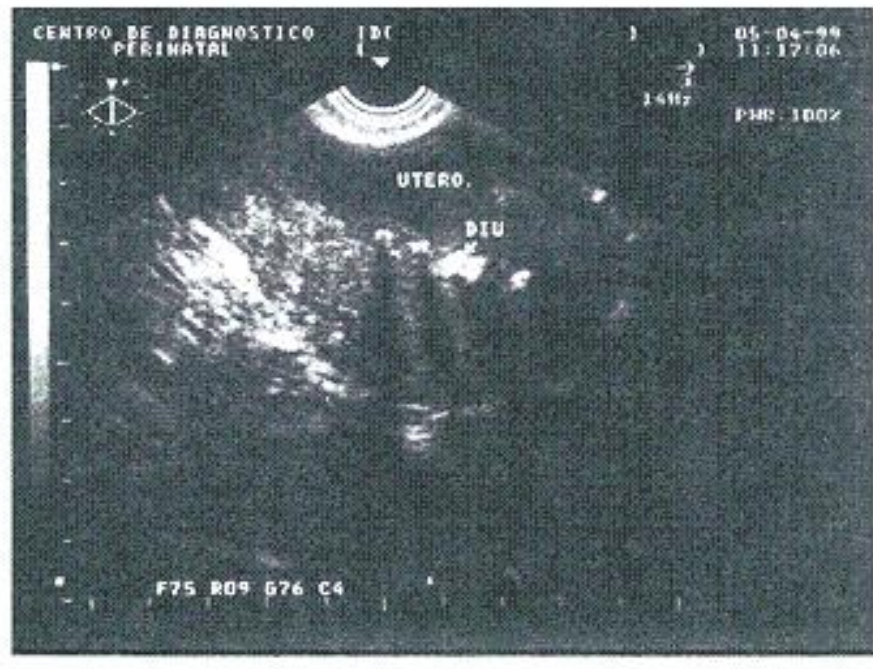

Figura 3, 0008i03

Un dispositivo intrauterino (Asa de Lippes) impide que las adherencias intrauterinas se vuelvan a presentar.

Siete pacientes se llevaron a cirugía para dilatación cervical bajo anestesia general. Siguiendo la técnica convencional para este procedimiento, utilizando bujías de Hegar (\# 4-5) avanzando a través del canal cervical, hasta tener la sensación de chocar con el fondo uterino, luego se realizan desplazamientos laterales tratando de llegar a las paredes laterales del útero.

Después de liberadas las adherencias mediante la dilatación, se les colocó una dispositivo intrauterino (Asa de Lippes), el mismo día se les inició estrógenos conjugados $2.5 \mathrm{mg} /$ día $/ 7$ días, continuando con $1.25 \mathrm{mg} / \mathrm{d}$ hasta completar 21 días. En todas se presentó sangrado por supresión y al $5^{\circ}$ día se continuó con un esquema cíclico secuencial con $1.25 \mathrm{mg}$ de estrógenos conjugados por 21 días, acompañando los 10 últimos días con $10 \mathrm{mg}$ de acetato de medroxiprogestesterona, por uno o dos ciclos más.

A 5 pacientes se les retiro el dispositivo intrauterino a los 2 meses y a 3 pacientes después de 3 meses. Tres pacientes con interés obstétrico se embarazaron en los 6 meses siguientes de haber retirado el dispositivo, lográndose 1 embarazo a término con recién nacido sano y 2 de ellas en la actualidad cursan embarazo de 6 y 8 meses respectivamente. Las 4 pacientes sin interés obstétrico continuaron con planificación hormonal, mensual, inyectable.

En una paciente (cuya historia refería cirugía de Strassman 1 año antes) no fue posible realizar la dilatación y dos pacientes sin interés obstétrico, con adherencias gruesas en la parte superior de la cavidad, después de explicarles la causa de su alteración prefirieron no someterse a ningún procedimiento.

\section{Conclusiones}

La sonohisterografía de comprobada utilidad en pacientes con hemorragia uterina anormal puede resultar de gran utilidad con pacientes en estudio de esterilidad como en el caso de sospechar un síndrome de Asherman.

La sonohisterografía que es un procedimiento de consultorio, no doloroso, sobre todo cuando se utilizan catéteres como los de inseminación intrauterina de solo $2.3 \mathrm{~mm}$ de diámetro $y$ que permite determinar con mucha aproximación la ubicación de las sinequias, como también su espesor, dándonos una idea de la posibilidad terapéutica ya sea la simple dilatación o la cirugía histeroscópica en caso de las adherencias gruesas.

La liberación de las adherencias intrauterinas con bujías de Hegar es un procedimiento sencillo y poco costoso para los casos de adherencias menores que fueron la mayoría en el presente estudio (70\%) y la histeroscopia en el caso de adherencias gruesas que son las de mayor riesgo para perforación uterina, al ocasionar una falsa vía cuando se realiza dilatación.

\section{BIBLIOGRAFIA}

1. O' Dowd MJ, Philipp EE. Historia de la Ginecología y la Obstetricia. Edika Med. 1a. Edición 1995; 248.

2. Gómez Tabarez G. Factor uterino en infertilidad. Endocrinología Reproductiva e Infertilidad. Artes Gráficas Univalle. 1a. Edición 1999; 532-5330

3. Hysteroscopic treatment of severe Asherman's syndrome and subsequent fertility. Capella-Allouc S; Hum Reprod, 1999 May.
4. Prevalence of Asherman's syndrome after secondary removal of placental remnants or a repeat curettage for incomplete abortion. Westendorp I.C; Hum Reprod, 1998 Dec.

5. Burbano Adrada E. Sonohisterografía: Un recurso diagnóstico en pacientes con hemorragia uterina anormal. Rey Col Obstet Ginecol 1988; 15: 169172 . 